\title{
Prevalence and Genotyping of Human Papillomavirus (HPV) in Female with High-Risk Behaviour in Dhaka, Bangladesh
}

\author{
Tahmina Sultana ${ }^{1}$, Mohsina Huq², Anadil Alam², Dipak Kumar Mitra² and Donald James Gomes ${ }^{1 *}$ \\ ${ }^{1}$ Department of Microbiology, University of Dhaka, Dhaka 1000, Bangladesh, ${ }^{2}$ RTI/STI Lab, Public Health Service Division, International Centre for \\ Diarrhoeal Disease Research, Bangladesh (ICDDR,B), 68 Shaheed Tajuddin Ahamed Sharani, Mohakhali, Dhaka 1212, Bangladesh
}

[Received 15 March 2008; Accepted 14 June 2008]

\begin{abstract}
In developing countries, cervical cancer is the most common cause of cancer related to mortality in women. But the epidemiology of human papillomavirus (HPV) in different areas of Bangladesh is largely unknown both in risk groups and in the general population. The objective of the present study was to determine the risk factors associated with having HPV and the prevalence of high-risk HPV types among women with highrisk behaviour and to assess its potential impact on preventive strategies as the sex workers are at increased risk for sexually transmitted infections (STI), HPV and hence cervical cancer. Cervical swab from 293 sex workers in Dhaka City between August and September 2003 and between February 2005 and May 2006 were screened for HPV DNA using an HPV short fragment (E6) polymerase chain reaction (PCR) based assay. HPV positive samples were genotyped with nested multiplex polymerase chain reaction (NMPCR) for the high-

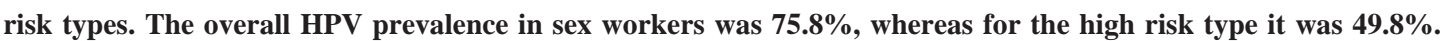
Prevalence of single genotype and multiple types of HPV was 33.1 and $16.7 \%$ respectively. The most prevalent high-risk HPV types, in order of prevalence rate, were HPV16, HPV18, HPV58, HPV45, HPV31 and HPV33. Both HPV 16 and HPV 18 were present in $21 \%$ of the cases. Targeting HPV 16 and 18 with prophylactic vaccines could possibly have an important impact on the incidence of invasive cervical carcinoma in this group of women. Primary prevention and cervical cancer screening programmes should be optimized more and run yearly among the general population. It is proposed to screen sex workers when they enter prostitution regardless of their age.
\end{abstract}

Keywords: Human papillomavirus (HPV), High-risk HPV types, Cervical cancer, Sex workers

\section{Introduction}

It is estimated that the incidence of new infections in developing countries, cervical cancer is often the most common cancer in women and may constitute up to $25 \%$ of all female cancers ${ }^{1}$. Cervical cancer which is caused by human papillomaviruses (HPVs) are small, nonenveloped viruses of about $55 \mathrm{~nm}$ in diameter containing the viral genome as circular double stranded DNA². The 'low risk' HPV types are associated with anogenital warts and condylomas, but do not confer an excess risk for cancer, whereas the 'high risk' types are associated with cervical dysplasias that have a considerable potential for progression to cancer $^{3}$. An important emerging factor in the development of cervical neoplasia is the role of HPV variants ${ }^{4}$. HPV variants differ in biological and chemical properties and in pathogenicity and oncogenicity.

Detection of high-risk human papillomavirus (HPV) infections might identify women who are at increased risk of development or progression of a cervical lesion ${ }^{5-7}$, and vice versa, negative tests have a very high negative predictive value for the development of a cervical lesion ${ }^{8-9}$.

The E2 and E1 papillomavirus proteins regulate DNA replication. At some stage when viral DNA gets integrated into the host genome, the E2 gene is inactivated that leads to a de-repression of the E6 and E7 viral oncogenes ${ }^{10}$. E6 protein of the high-risk HPV types associates with the product of tumour suppressor gene p53 and the HPV16 E7 protein to pRb that lead to cancer ${ }^{11}$.

Although HPV is essential to the transformation of cervical epithelial cells, it is not sufficient, and a variety of cofactors such as multiple sexual partners, exposure to sexually transmitted disease (STD), immunosuppressant etc. influence whether cervical cancer will develop ${ }^{12}$. So area or country wise study of epidemiology and genotyping of HPV is needed immediately. Viral ecology studies are also needed to assess the effect of vaccination on HPV type

*Corresponding authors:

Dr.Donald James Gomes, Professor, Department of Microbiology, University of Dhaka, Dhaka 1000, Bangladesh

Tel (Office): (02) 9661920-73, Ext 7739; Tel (Home): (02) 8362232; Cell: 01817 016815; Fax: +880 (02) 8615583; E-mail: donaldjgomes@hotmail.com 
distribution in the population and in disease. Because even if some vaccines are found to be safe and efficacious in some settings it cannot be assumed that the same efficacy will hold in other geographical and ecological situations. Keeping these views, this investigation was carried out to find out the risk factors related to HPV and the exact prevalence and the distribution patterns of HPVs within the high-risk group women in Dhaka City.

\section{Materials and Methods}

A total of 293 women with high-risk sexual behaviour with an age range from 12 years to 45 years were studied. Participants were tested for the presence or absence of ulcer, lower abdominal pain, and genital warts. The collected cytobrush was placed in a storage tube containing $400 \mathrm{ml}$ of phosphate-buffered saline, snap frozen in liquid nitrogen, and stored at $-70^{\circ} \mathrm{C}$ until further processing.

Total DNA extracted from cervical scrapes was performed according to the Oxford protocol ${ }^{13}$. One hundred nanogram (ng) of total extracted DNA was used for polymerase chain reaction (PCR) amplification. HPV cannot be cultured in the laboratory from clinical specimens and immunologic assays are not adequate for detection of HPV infections. The PCR technique is the most sensitive HPV detection method, being able to detect one viral genome in $10^{5}$ cells $^{14}$.

The procedures of both first round (HPV short fragment, E6, PCR) and second round (nested multiplex PCR, NMPCR) and the primer sequences for PCR were chosen according to Sotlar and coworkers ${ }^{13}$. First-round PCR with GP-E6/E7 consensus primers should facilitate initial amplification of the genomic DNA of all known mucosal HPV genotypes and provide enough material to be amplified in numerous nested PCRs with type-specific primers for HPV genotypes 16, 18, 31, 33, 45 and 58.

The calculations were performed with the statistical software package SPSS version 11.5. The chi-square test was used to assess the statistical significance of association in prevalence of HPV by different variables. $p<0.01$ was considered significant to take into account.

\section{Results and Discussion}

No information is available at present on HPV prevalence or cervical cancer incidence or mortality among general population or among sex workers in Dhaka City and in other areas of Bangladesh.

\section{Risk factors associated with HPV infection}

Women with 20 years or less than 20 years of age have 1 times more chance of having HPV than the women of more than 20 years of age (Table 1). But this finding does not represent the whole population (as 95\% CI $=0.9-2.4$ ). This result is similar to the other studies where HPV prevalence declines with increasing age ${ }^{15}$. The HPV prevalence is declining in sex workers with age despite continuously high sexual activity, most likely indicating that an immune response is acquired over time ${ }^{16}$. Relation of risk factors such as pregnancy, presence of ulcer, lower abdominal pain, genital warts and presence of HPV were statistically non-significant (Table 1).
Table 1. Risk factors associated with human papillomavirus (HPV) DNA detection in women with high-risk behaviours

\begin{tabular}{|c|c|c|c|c|}
\hline Variable & $\begin{array}{c}\text { No. }(\%) \\
\text { HPV positive }\end{array}$ & $\begin{array}{c}\text { No. (\%) } \\
\text { HPV negative }\end{array}$ & $p$ value & $\begin{array}{l}\text { Crude OR } \\
(95 \% \text { CI })\end{array}$ \\
\hline \multicolumn{5}{|l|}{ Age, year } \\
\hline$\leq 20$ & $42(28.8)$ & $55(37.4)$ & 0.1 & 1.48 \\
\hline$>20$ & $104(71.2)$ & 92 (62.6) & & $(0.9-2.4)$ \\
\hline \multicolumn{5}{|l|}{ Pregnancy } \\
\hline Parity & $74(50.7)$ & 79 (53.7) & 0.6 & 0.89 \\
\hline No parity & 72 (49.3) & $68(46.3)$ & & $(0.6-1.4)$ \\
\hline \multicolumn{5}{|c|}{ Presence of ulcer } \\
\hline Yes & $1(0.7)$ & $3(2.0)$ & 0.32 & 0.3 \\
\hline No & 145 (99.3) & $144(98.0)$ & & $(0.03-3.2)$ \\
\hline \multicolumn{5}{|c|}{$\begin{array}{l}\text { Clinical } \\
\text { symptoms of } \\
\text { lower abdominal } \\
\text { pain }\end{array}$} \\
\hline Yes & $10(6.8)$ & 17 (11.6) & 0.16 & 0.56 \\
\hline No & $136(93.2)$ & $130(88.4)$ & $(0.2-1.3)$ & \\
\hline \multicolumn{5}{|l|}{$\begin{array}{l}\text { Presence of } \\
\text { genital wart }\end{array}$} \\
\hline Yes & $5(3.4)$ & $10(6.8)$ & 0.19 & 0.49 \\
\hline No & $141(96.6)$ & $137(93.2)$ & & $(0.2-1.5)$ \\
\hline
\end{tabular}

OR = Odds ratio; $\mathrm{CI}=$ Confidence interval.

Amplification of human papillomavirus (HPV) DNA with general primers

The E6 PCR product size varies from 602 to 666 bp (Figure 1). Viral DNA of many other high-risk and low-risk HPV types should be amplified as well.

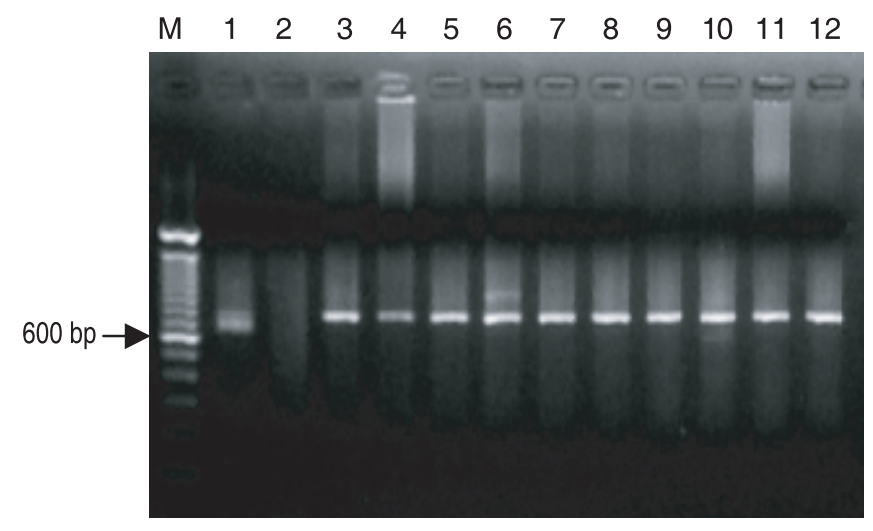

Figure 1. Amplification of human papillomavirus (HPV) DNA with consensus primers GP-E6/E7 and GP-E7-5B/6B. The PCR products are 666 bp in size. $M=$ Marker; Lane 1: Positive control, Lane 2: Negative control, and Lane 3-12: Amplification product of HPV DNA using consensus primers.

Amplification of human papillomavirus (HPV) DNA with typespecific primers

The length of these amplification products ranged from $457 \mathrm{bp}$ (HPV-16) down to 151 bp (HPV-45), thus allowing easy discrimination and identification of the underlying HPV type by simple gel electrophoresis (Figure 2). 


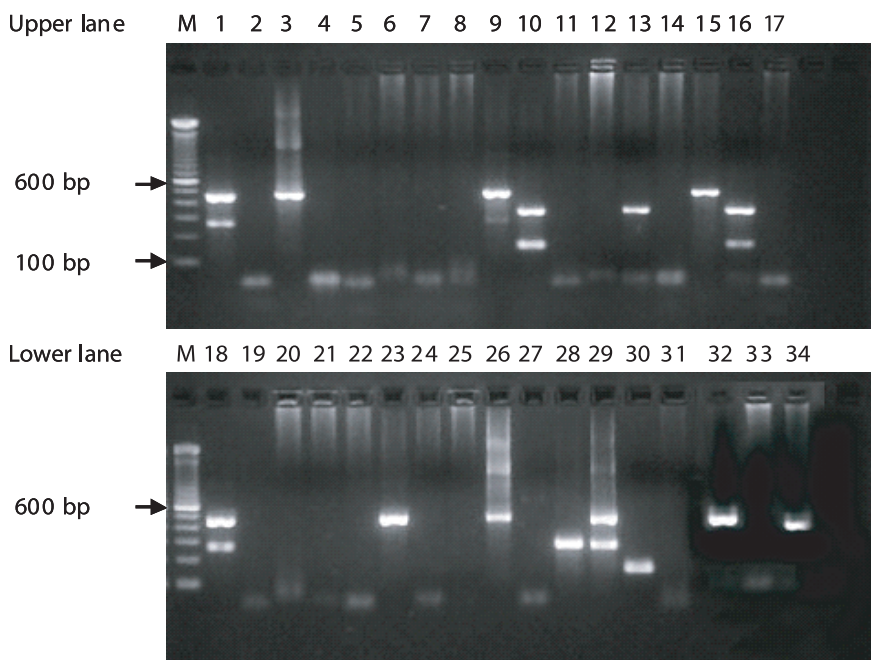

Figure 2. Nested multiplex polymerase chain reaction (NMPCR). Lane 1 and 18: Positive control (457 and $263 \mathrm{bp}$ band size), Lane 2 and 19: Negative control. Lane 29: Type 16 and type 31 positive, Lane 10: Type 18 and type 45 positive, Lane 28 and 34: Type 58 and type 33 positive.

\section{Prevalence of human papillomavirus (HPV) genotypes}

The prevalence of genital HPV (both high-risk and low-risk) types in the sex workers was as high as $75.8 \%$, whereas for the high-risk types it was $49.8 \%$ (Figure 3). The high prevalence of HPV in Dhaka City among women with high-risk behaviour is noteworthy as this group can be a threat for the mass in spreading HPV. Infection with any one of the high-risk HPV types and infection with more than one type was also not so lower. The presence of multiple HPV genotypes tended to increase with the severity of cervical disease.

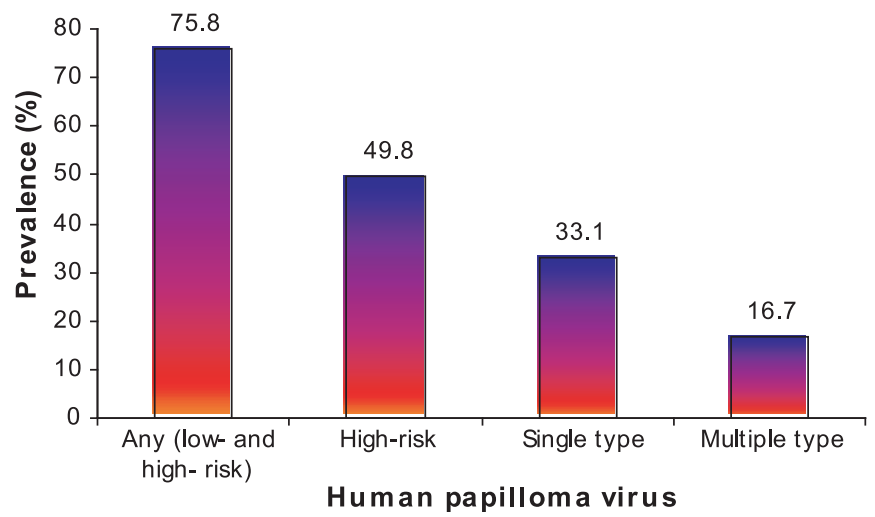

Figure 3. Prevalence of different combination of human papillomavirus $(H P V)(n=293)$.

Prevalence of high-risk human papillomavirus (HPV) genotypes among sex workers

As shown in Table 2 the highest prevalence rate was observed for the genotype 16, 18 and for type 58. In a study, it was found that HPV type 16 (87\% of all HPV-positive tumours) was the most prevalent DNA in patients; this was followed by HPV 18 in just
$13 \%$ of all cases ${ }^{17}$. These results are in agreement with the epidemiological status of most commonly found HPV types in Bangladesh. Centres for Disease Control and Prevention (CDC) also reported that HPV type 16 is the most common high-risk type ${ }^{15}$.

Table 2. Human papillomavirus (HPV) genotype and their percentage among women with high-risk behaviours

\begin{tabular}{lcc}
\hline HPV genotype & $\begin{array}{c}\text { Total No. of } \\
\text { positive sample }\end{array}$ & $\begin{array}{c}\text { Percent in total } \\
\text { sample }(\mathrm{n}=293)\end{array}$ \\
\hline HPV 16 & 97 & 33.1 \\
HPV 18 & 41 & 14.0 \\
HPV 31 & 12 & 4.1 \\
HPV 33 & 9 & 3.1 \\
HPV 45 & 14 & 4.8 \\
HPV 58 & 32 & 10.9 \\
\hline
\end{tabular}

Prevalence of co-infection

Percentage of co-infection with HPV 16 and HPV 18 was 21\% that was the highest one (Table 3). These prevalence rates are much lower than the prevalence among invasive cervical cancer cases in other areas of the world. From this analysis we can interpret that infection with one type does not inhibit the presence of another one and co-infection is not the rare case.

Table 3. Percentage of co-infection of different human papillomavirus (HPV) genotypes

\begin{tabular}{lrrrrrr}
\hline HPV genotype & \multicolumn{7}{c}{ HPV genotype } \\
\cline { 2 - 7 } & 16 & 18 & 31 & 33 & 45 & 58 \\
\hline 16 & 21 & 4 & 4 & 2 & 12 \\
18 & 4 & 5 & 5 & 2 & 3 & 7 \\
31 & 4 & 2 & 1 & 1 & 2 & 1 \\
33 & 2 & 3 & 2 & 1 & 1 & 1 \\
45 & 12 & 7 & 4 & 1 & 2 & \\
58 & & & & & & \\
\hline
\end{tabular}

Considering our findings, prophylactic vaccination against HPV type 16 and type 18 could possibly have the most important impact on the incidence of cervical cancer among sex workers. Further investigation is necessary to analyze the oncogenic potential of other high prevalent HPV genotypes, in order to establish the HPV types that future vaccines should target. Heterogeneity in human papillomavirus type distribution among women from different populations should be taken into account when developing screening tests for the virus and predicting the effect of vaccines on the incidence of infection. A wide population based epidemiological study is mandatory to define the exact picture of this in our country. This would not only have an impact on the incidence of HPV dependent neoplasia, but also on the prevalence of other sexually transmitted infections in our country. 


\section{References}

1. Harro CD, Pang Y-YS, Roden RBS, Hildesheim A, Wang Z, Reynolds MJ, Mast TC, Robinson R, Murphy BR, Karron RA, Dillner J, Schiller JT \& Lowy DR. 2001. Safety and immunogenicity trial in adult volunteers of a human papillomavirus $16 \mathrm{~L} 1$ virus-like particle vaccine. J Natl Cancer Inst. 93: 284-292.

2. Pfister H. 1984. Biology and biochemistry of papillomaviruses. Rev Physiol Biochem Pharmacol. 99: 111-181.

3. Lorincz AT, Reid R, Jenson AB, Greenberg MD, Lancaster WD \& Kurman RJ. 1992. Human papillomavirus infection of the cervix: Relative risk associations of 15 common anogenital types. Obstet Gynecol. 79: 328-337.

4. Giannoudis A \& Herrington CS. 2001. Human papillomavirus variants and squamous neoplasia of the cervix. J Pathol. 193: 295-302.

5. Cox JT, Lorincz AT, Schiffman MH, Sherman ME, Cullen A \& Kurman RJ. 1995. Human papillomavirus testing by hybrid capture appears to be useful in triaging women with a cytologic diagnosis of atypical squamous cells of undetermined significance. Am J Obstet Gynecol. 172: $946-954$.

6. Cuzick J, Szarewski A, Terry G, Ho L, Hanby A, Maddox P, Anderson M, Kocjan G, Steele ST \& Guillebaud J. 1995. Human papillomavirus testing in primary cervical screening. Lancet. 345: 1533-1536.

7. Richart RM. 1995. Screening. The next century. Cancer. 76: 19191927.

8. Burger MP, Hollema H, Pieters WJ \& Quint WG. 1995. Predictive value of human papillomavirus type for histological diagnosis of women with cervical cytological abnormalities. BMJ. 310: 94-95.
9. Rozendaal L, Walboomers JM, van der Linden JC, Voorhorst FJ, Kenemans P, Helmerhorst TJ, van Ballegooijen M \& Meijer CJ. 1996. PCR-based high-risk HPV test in cervical cancer screening gives objective risk assessment of women with cytomorphologically normal cervical smears. Int J Cancer. 68: 766-769.

10. Rosales R, LoÂpez-Contreras M \& Cortes RR. 2001. Antibodies against human papillomavirus (HPV) Type 16 and 18 E2, E6 and E7 proteins in sera: Correlation with presence of papillomavirus DNA. J Med Virol. 65: 736-744.

11. Nevins JR. 1992. A closer look at E2F. Nature. 358: 375-358.

12. Noel M. 2003. Human papillomavirus and cervical cancer. Available at: http//www.reproline.jhu.edu. Accessed 25 September 2007.

13. Sotlar K, Diemer D, Dethleffs A, Hack Y, Stubner A, Vollmer N, Menton S, Menton M, Dietz K, Wallwiener D, Kandolf R \& Bultmann B. 2004. Detection and typing of human papillomavirus by E6 nested multiplex PCR. J Clin Microbiol. 42(7): 3176-3184.

14. de Villiers EM. 1992. Laboratory techniques in the investigation of human papillomavirus infection. Genitourin Med. 68: 50-54.

15. CDC. 2004. National Prevention Information Network, Centers for Disease Control and Prevention (CDC). Rockville, Maryland.

16. Kjaer SK, Svare EI, Worm AM, Walboomers JM, Meijer CJ, van den Brule AJ. 2000. Human papillomavirus infection in Danish female sex workers. Decreasing prevalence with age despite continuously high sexual activity. Sex Trans Dis. 27(8): 438-445.

17. Zumbach K, Kisseljov F, Sacharova O, Shaichaev G, Semjonova K, Pavlova L, Pawlita M. 2000. Antibodies against oncoproteins E6 and E7 of human papillomavirus types 16, and 18 in cervical carcinoma patients from Russia. Int J Cancer. 85: 813-318. 